\title{
La construcción de la Base Nacional Común Curricular (BNCC) de Historia en Brasil: entre diálogos, tensiones y controversias
}

\author{
Doi:https://doi.org/ 10.25100/hye.v15i53.8728 \\ Artículo recibido: 19-02-2018 Artículo aceptado: 10-09-2019
}

\section{Luis Fernando Cerri}

Es Profesor y licenciado en Historia de UNICAMP (Universidad Estatal de Campinas),Doctor en Educación de la misma institución. Realizo un Pos-Doctorado en Educación en UNLP (Universidad Nacional de la Plata), de igual forma es PosDoctor en Ciencias Políticas por la Universidad Federal de Paraná. Su producción se centra en la Enseñanza de la Historia y Didáctica de la Historia.

Universidad Estadual de Ponta Grossa, Brasil.

Correo electrónico: lfcronos@yahoo.com.br

ORCID: 0000-0002-9650-0522

\section{Maria Paula Costa}

Es Licenciada en Historia por la Universidad Estatal Paulista (Brasil), además cuenta con un Máster y Doctorado en Historia de la misma institución. Actualmente es profesora adjunta en la Universidad Estatal del Medio Oeste (Unicentro) en el Departamento de Historia de Guarapuava (Brasil). Trabaja en el área de Enseñanza de Historia, y centra susinvestigaciones en la Enseñanza de la Historia.

Universidad Estadual do Centro-Oeste- Pr Unicentro.

Correo electrónico: paulaecosta@gmail.com

ORCID: 0000-0002-6750-2887

Forma de citar este artículo: Cerri, Luis Fernando y María Paula Costa "La construcción de la Base Nacional Común Curricular (BNCC) de Historia en Brasil: entre diálogos, tensiones y controversias". Historia y Espacio, vol. 15 n 53 (2019): 67-90. Doi.org/ 10.25100/hye.v15i53.8728

Artículo Tipo 3: de reflexión 


\section{La construcción de la Base Nacional Común Curricular (BNCC) de Historia en}

\section{Brasil: entre diálogos, tensiones y controversias}

Resumen: Brasil vive un turbulento momento político que tuvo su primer auge con el golpe jurídico-parlamentario contra la presidenta Dilma Rousseff. Mismo con un proceso en curso de inestabilidad política y económica se da continuidad a una serie de propuestas en el campo educativo, entre las que se inserta la construcción de una Base Nacional Común Curricular. El objetivo de este texto es problematizar como algunos historiadores se posicionan frente a la publicación, en 2015, de la primera versión de la Base Nacional Común Curricular para el componente Historia. Las disputas y conflictos ocurrieron, pues la BNCC proponía una remodelación en las narrativas históricas enfatizando la Historia de Brasil y sus orígenes amerindias y africanas balizando el lugar de la historia antigua y medieval. Las críticas que siguieron a la publicación de este documento preliminar no se restringieron al espacio de las universidades y de las asociaciones representativas, pero involucraron a los editores y autores de libros didácticos, políticos conservadores, religiosos fundamentalistas y periodistas sensacionalistas. Este artículo analiza una muestra de textos académicos y periodísticos que estructuraron el debate y propone un análisis preliminar de los argumentos utilizados y su relación con las posturas político-académicas, identificando posibles categorías para futuros análisis de contenido.

Palabras clave: Currículo, Enseñanza de historia, Eurocentrismo, Negacionismo científico.

\section{The making of National Curricular Common Basis of History at Brazil: between dialogues, tensions and controversies}

Abstract: Brazil is experiencing a troubled political moment that had its first culmination with the judiciary-parliamentary coup against President Dilma Rousseff. Even with an ongoing process of political and economic instability, a series of proposals in the field of education are being pursued, among which is the construction of a National Curricular Common Base. The aim of this text is to problematize how some historians position themselves before the publication, in 2015, of the first version of the National Curricular Common Base for the History component. The disputes and conflicts occurred because the BNCC proposed a remodeling in the historical narratives emphasizing the History of Brazil and its Amerindian and African origins instead of the ancient and medieval history. Criticism following the publication of this preliminary document was not restricted to the space of universities and representative associations but involved editors and authors of textbooks, conservative politicians, fundamentalist religious and tabloid journalists. This article analyzes a sample of academic and journalistic texts that structured the debate and proposes a preliminary analysis 
of the arguments used and their relationship with political-academic postures, identifying possible categories for further content analysis.

Keywords: Curriculum, History teaching, Eurocentrism, Scientific denialism.

\section{Luis Fernando Cerri - Maria Paula Costa}

\section{La construcción de la Base Nacional Común Curricular (BNCC) de Historia en Brasil: entre diálogos, tensiones y controversias}

\section{Introducción}

Las reformas curriculares en Brasil no son infrecuentes, ya que muchas veces se muestran como una alternativa rápida de modificación en el sistema educativo. Utilizada a menudo como "bandera" en las elecciones, los grupos que ascienden al poder buscan redibujar el mapa de la educación de acuerdo con sus intereses y bajo la justificación de proporcionar un nuevo trazado a ese territorio, prometen, al menos en el marco del discurso, el derecho del ciudadano a una enseñanza de calidad.

En este vasto territorio la disciplina de Historia se destaca y provoca discusiones a cada reforma propuesta. Si se ha retrocedido a los años 1970 en Brasil, donde se vivía una dictadura militar, percibimos como despojaron la enseñanza de la Historia y la Geografía sobre la égida de lo que fue llamado de Estudios Sociales y hasta hoy sentimos el impacto de ese despojo ${ }^{1}$.

Las redefiniciones educativas en la actual sociedad brasileña abarcan todos los niveles de enseñanza, de las series iniciales a la educación superior. Se evidencia que esas propuestas surgen en un momento político conturbado

1 En la reforma educacional de la dictadura brasileira basada en la Ley 5692/1971 las disciplinas de Historia y Geografía fueran mezcladas y descaracterizadas en una nueva disciplina llamada Estudios Sociales. Gran parte de la lucha de historiadores, geógrafos y profesores de estas dos disciplinas contra la dictadura se ha concentrado en la lucha en contra los Estudios Sociales y por la restauración de las disciplinas de Historia y Geografía. Poco antes, en 1969, el gobierno dictatorial había creado los profesorados de corta duración, bajo el pretexto de que había poca mano de obra docente, desvalorando la formación de profesores para la Educación Básica. Principios tremendamente semejantes orientaron las reformas y políticas educaciones del gobierno de Michel Temer y siguen en el gobierno Bolsonaro. 
donde un golpe que ya venía siendo elaborado y preparado derribó a la presidenta Dilma Rousseff en 2016. Se suma a eso que el proyecto de reformas educativas fue acompañado por cambios en el Ministerio de Educación, no sólo de ministro, como del equipo.

En medio de ese escenario sombrío e inestable en el país se publica una serie de documentos que establecen propuestas de reestructuración del sistema educativo, siendo éstas: la Reforma de la Enseñanza Media, alteración en el Programa Nacional del Libro Didáctico (PNLD), cambios en el Examen Nacional de la Enseñanza Media (ENEM), nuevas Directrices Curriculares Nacionales para la formación inicial a nivel superior (cursos de profesorado) y la propia definición de una Base Nacional Común Curricular (BNCC) 2 .

La necesidad de la construcción de una Base Nacional Curricular en un país de grandes dimensiones territoriales se vuelve a nuestro ver, un paso importante, pues además de definir los objetivos educativos del aprendizaje en pleno siglo XXI, permite construir directrices que orienten el acceso al conocimiento para todos las brasileñas y brasileños, garantizando la inclusión de ellos como protagonistas en la sociedad actual.

Es importante resaltar que la BNCC no es sinónimo de currículo, pensar de ese modo restringiría la complejidad que define e involucra el currículo. En este sentido, tenemos que comprender que su texto debe orientar la construcción de los currículos, configurándose en un documento que presenta principalmente un rol estructurado de derechos de aprendizaje, contenidos, metodologías y conceptos, por lo que implica una cuestión de elección sobre qué mantener y qué abandonar, qué destacar y qué considerar secundario.

En lo que se refiere a las definiciones de los contenidos de Historia, éstos revelan qué sociedad, qué espacio y tiempo histórico será presentado y debatido en el ámbito escolar. Por eso, la elaboración y elección de las narrativas históricas en el currículo se chocan con la producción historiográfica y despiertan intereses de las áreas de investigación en las universidades. No es incomún que los docentes universitarios que dan clases en profesorado no

2 El Plan Nacional de Educación de Brasil es una ley promulgada por la presidenta Dilma Rousseff (Ley 13.005/2014) tras un amplio debate en la sociedad civil, y estableció metas para los siguientes diez años para la educación brasileña. Entre sus determinaciones estuvo la sistematización de contenidos y competencias intelectuales esenciales comunes para toda la educación nacional, que ha sido concretada en forma de un documento de bases curriculares que involucra todas las disciplinas, la Base Nacional Común Curricular (BNCC). Las críticas a estos procesos incluyen principalmente la larga influencia de fundaciones privadas vinculadas a poderosos intereses financieros. 
articulen su producción académica a la historia enseñada en la escuela y ni contemplen la posibilidad de producir conocimiento en la educación básica. Sin embargo, al desconfiar de cualquier riesgo, o posible amenaza de retirada o pérdida de espacio de su área del currículo y consecuentemente, de las páginas de los libros didácticos, salen en defensa de la importancia del área en la cual producen para el currículo escolar, recuerdan la existencia de la escuela y la importancia de la articulación de lo que producen y de las narrativas que circulan diariamente en ella. La cuestión que se impone es: ¿en qué medida el aprendizaje histórico de niños y jóvenes en edad escolar aparece contemplada en ese debate de disputa de poder?

Considerando la importancia de reflejar los significados de este proceso en curso en Brasil, es que este texto buscó centrarse en la aparente contradicción en torno a los debates y documentos publicados sobre la primera versión de la BNCC a finales de 2015 y principios de 2016. Así como comprender la ausencia de este mismo debate sobre la publicación de la segunda y tercera versiones de BNCC Historia ya que, en mayo de 2016 tras varias críticas, el modelo quatripartito (Edad Antigua, Media, Moderna y Contemporánea) retornó triunfante ya en la segunda versión, aún bajo el gobierno de Rousseff, y su diseño más tradicional y conservador fue restaurado en la versión final, de enero de 2017.

\section{Entre la selección de contenidos y el derecho al aprendizaje histórico}

La primera versión de la Base Nacional Curricular para la disciplina de Historia (BNCC-H), lanzada en septiembre de 2015, proponía una reducción drástica a los contenidos de historia antigua y medieval en detrimento de una, hasta entonces, perspectiva innovadora que optó por privilegiar la historia de Brasil y la historia reciente. De este modo el enfoque general de la narrativa de la historia fue revisado desde los principios. En los enfoques predominantes en los currículos brasileños hasta entonces, sea en los enfoques tradicionales, sea en los abordajes llamados de historia integrada, se trataba de enseñar primero la historia general y después la historia de Brasil, lógica que siempre ha implicado una jerarquización tácita. En esta jerarquización, la historia de Brasil es narrada por una mirada extranjera, a partir de un enfoque europeo: es necesario contar toda la historia general antes de la llegada de los europeos al litoral del futuro Brasil para que la historia nacional brasileña entre en escena. Además, el foco narrativo de la historia en la escuela hasta hoy ha girado en torno al concepto 
de nación: Brasil colonial, Brasil imperial, Brasil republicano, por más que, a rigor, no exista Brasil antes de la independencia.

Este enfoque también se repite en la enseñanza superior, según Selva Guimarães Fonseca la historia de Brasil es concebida dentro de los marcos de la historia europea y con la asunción de un punto de vista europeizado.

O eurocentrismo foi aplicado de forma marcante não só nos programas de ensino, mas também na pesquisa histórica e na organização dos currículos dos cursos superiores em História. O currículo mínimo do curso de História, de acordo com a Resolução de 19 de dezembro de 1962, é basicamente constituído de História Antiga, Média, Moderna e Contemporânea, além de História da América e do Brasil. No caso da pesquisa, um bom exemplo é o levantamento dos temas das teses e dissertações defendidas na Universidade de São Paulo a partir de 1939. Nele é evidente a opção de autores brasileiros por temas e tratamentos eurocêntricos ${ }^{3}$.

Se evidencia que esa resistencia en alterar la mirada de la narrativa de la Historia de Brasil está articulada a una tradición que construyó las bases del pensamiento histórico sólo con una opción de lectura. Así, no se ha concebido, en el ámbito escolar, traducir las orientaciones de la Ley 13.645/ 2008 sobre la historia indígena en una enseñanza de historia que extrapole la forma nacional, lidiando con el pasado indígena en América o con la condición supranacional de la época de la colonia, integrada por medio del océano Atlántico en los intercambios económicos, migratorios y culturales con África, Europa y otras partes de América. Es importante resaltar que la opción por el foco en Brasil no corresponde necesariamente a abandonar la historia general, ni a un proyecto vulgarmente nacionalista de enseñanza, sino un cambio de foco y de prioridades de contenido. Guardadas las diferencias y debidas proporciones, se trata de una alternativa ya asumida en Argentina desde los años 1990.

Es importante recordar que la opción por el recorte cronológico inicial en el siglo XVI no imposibilita referencias a los períodos anteriores en diversos espacios, culturas y contextos, sino que lo somete a una nueva lógica de organización de los contenidos. Esta opción no ha sido apropiadamente discutida en términos de lo que efectivamente proponía y significaba en términos curriculares y educativos, pero ha sido menoscabada en el debate

3 Selva Fonseca, Caminhos da História Ensinada (Campinas: Papirus, 1993), .51.

${ }^{4}$ Gonzalo de Amézola, Esquizohistoria. (Buenos Aires: Zorzal, 2008), 69. 
cómo "brasilcentrismo", a la izquierda y a la derecha, en la comunidad académica y en la comunidad externa (guardadas las proporciones e intensidades) ${ }^{5}$.

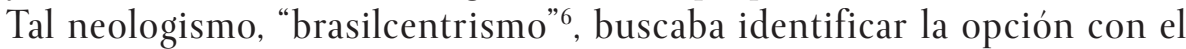
eurocentrismo, como su contraparte, pero en la misma categoría de significante y significado. Sin embargo, la mayoría de las críticas académicas y progresistas asintió que la propuesta de una alternativa al eurocentrismo, aunque la consideraba torpe, era un paso adelante. Por lo tanto, el eurocentrismo, para ese campo, no era la alternativa para el "brasilcentrismo", aunque permanecía, sí, una alternativa a las críticas más conservadoras, tanto historiográfica y políticamente. Es legítimo preguntarse cual sería entonces la opción, ya que eran rechazados tanto el eurocentrismo como el "brasilcentrismo", en las orientaciones curriculares ¿Una narración policéntrica? ¿"A-céntrica”? ¿Habría antecedente o base, en la historia de los currículos y de las narrativas didácticas, para una estructura de contenido con varios centros o sin centro alguno? ¿Estarían los críticos del "brasilcentrismo” efectivamente proponiendo concretamente otros focos narrativos? El hecho es que no fue necesario hacer efectivamente ninguna contrapropuesta para obtener ventaja en el debate: el uso del neologismo y el tono del debate facilitó la asociación con otra forma de discurso de alta aceptación en el justo momento del proceso de impeachment: el de negación de la ciencia por medio de una condena anticipada de los científicos de Humanas y Sociales por "exceso de ideología”. A eso se ha prestado, antes de todos los otros, el propio ministro de la Educación de la presidenta Dilma Rousseff en este momento. Esta estrategia, que se puede considerar una falacia ad hominem, dispensa al atacante de discutir efectivamente la propuesta y de ofrecer alternativas y soluciones, y ha sido ampliamente usada por organizaciones reaccionarias como el movimiento Escola Sem Partido ${ }^{7}$. Evidentemente, se trata de una aproximación bastante incómoda, no por ser identificada, sino por su propia existencia: una estrategia argumentativa común entre una organización de la sociedad civil que práctica una forma de negacionismo científico (contra las Ciencias Humanas) y se asocia con otras

5 La amplia aceptación a esta crítica por personajes y grupos tan distintos en términos políticos y en términos de posiciones en el tejido social es, por si sola, un tema fundamental para investigaciones posteriores en el marco de la ciencia política y antropología, entre otros.

6 Neologismo no tan nuevo

7 Gaudêncio Frigoto, "A gênese das teses do Escola Sem Partido [...]" en Escola "Sem" Partido: Esfinge que ameaça a educação e a sociedade brasileira. Ed. Gaudêncio Frigoto (Rio de Janeiro: UERJ, LPP, 2017), 27. 
(en contra las Ciencias Biológicas y Exactas, en los casos de confrontación entre las narrativas religiosas y las científicas), estrategia argumentativa de la que se aproximaron inadvertida y peligrosamente algunos sectores del gobierno Dilma Rousseff y de la propia academia ${ }^{8}$. Cleto ${ }^{9}$, por ejemplo, identifica que las primeras críticas de aquellos historiadores a la propuesta están involucradas en una concepción conservadora (formalista y no sustantiva) de igualdad, como base para la ciudadanía. La intervención de Magnoli y Barbosa ${ }^{10}$ también trae, de modo subyacente, el rechazo a la política de cuotas para negros, ligada a la perspectiva formalista de igualdad.

A pesar de muchas manifestaciones, a lo largo del debate, en cuanto a la falta de transparencia en el criterio para la formación de los equipos que redactó la versión preliminar, el hecho es que la lectura del material deja claro que la mayor parte de estos equipos fue compuesta por representantes de las secretarías municipales y estatales de Educación, con la asesoría de profesores universitarios de diversas regiones del país. Es decir, se trata de un criterio orientado a garantizar la representatividad de los órganos ejecutivos que quedarían responsables por implantar la BNCC, más que la representatividad de entidades de historiadores. Si, diferente de lo que pasó con la experiencia de la primera versión de la BNCC de Historia, los equipos hubiesen sido formados por académicos reconocidos, principalmente si representasen una sola línea de pensamiento, probablemente el documento resultante sería menos susceptible al tipo de críticas que recibió de los profesores universitarios y sus entidades. Tendría, probablemente, mayor coherencia interna y sintonía con los grandes debates historiográficos y educativos del momento. Nada de eso, sin embargo, fue suficiente para que modelos anteriores, como los Parámetros Curriculares Nacionales, fuesen efectivamente acogidos en las varias esferas del sistema educativo y puestos en práctica. El costo, sin embargo, fue un documento lleno de flancos para la crítica típicamente académica (pero no típica del debate curricular o de la política educativa), que pretendemos explorar un poco mejor más adelante.

La composición del equipo, regional y académicamente diversa, con representantes de estados y municipios y con el eje desplazado hacia el Norte y

8 Sobre el negacionismo más amplio, cómo fenómeno contemporáneo, ver Lewandowski et al., 2013, y Morrison, 2011.

9 Murilo Cleto, “Quem tem medo de outra História?” Revista Fórum, N. 230, 2016.

${ }^{10}$ Demétrio Magnoli y Elaine Cenise Barbosa, "Proposta do MEC para ensino de história mata a temporalidade”, Folha de São Paulo. 8 de noviembre de 2015. 
el Nordeste puede explicar una parte importante de la osadía que ella asumió en reducir drásticamente los contenidos de historia antigua y medieval, y reenfocar los contenidos de la Historia de Brasil. En nuestro punto de vista, la explicación para ello es más simple que todas las teorías y acusaciones planteadas. Se trata simplemente de tratar de enfrentar los efectos perjudiciales del tratamiento de la disciplina Historia en el aula como una especie de autobús lleno en el que cada vez nuevos pasajeros insisten en subir. El primer desafío enfrentado, por lo tanto, fue el de escoger contenidos en detrimento de otros, con el fin de reducir la gigantesca carga de asuntos que profesores y estudiantes deben (o deberían) dar cuenta. Además, la tarea de intentar dar todos los asuntos hoy pedidos en los currículos de Historia es irracional y generalmente fracasada. Buscar vencer todos los contenidos es la garantía de una enseñanza y de un aprendizaje superficial y memorístico, del tipo útil para ser aprobado en exámenes concurridos y olvidarse enseguida.

Históricamente, la enseñanza escolar de Historia en Brasil ha significado manejar una estructura canónica de contenidos, edificada originalmente en Europa, insertada en el sistema educativo de un estado monárquico y nobliarquico, para la formación de grupos dirigentes de élite en el "mundo de los blancos". Desde entonces, ese modelo ha sido mantenido con pocos cambios estructurales, ya que las iniciativas de historia temática ${ }^{11}$ no tuvieron suficiente difusión para confrontarlo. Al término del contexto que le dio origen, el modelo siguió, ahora sostenido por sí mismo, preso a la lógica interna al sistema educativo, más autorreferente que dialógico, reproduciéndose en la formación de estudiantes que, a su vez, se convertirían en padres, profesores e historiadores, generando un vicioso círculo de hierro. Así, seguimos eurocéntricos, curiosamente nacionalistas (reivindicando en ese nacionalismo casi exclusivamente la herencia europea) y lineales. Otras formas de enfrentamiento de este modelo tienden a sumar a él nuevas demandas, como un árbol de navidad a la que agregamos cada vez más adornos. La eficiencia de esta enseñanza de historia confusa y enciclopédica, cargada de temas y contenidos sin fin, camina hacia la nulidad. En un tsunami de hechos, informaciones, conceptos, imágenes, considerando las pocas clases de historia, es difícil establecer otras relaciones que no sean memorización, zapeo de contenidos y aligeramiento. Para los estudiantes, principalmente de la Enseñanza Media, (en que las clases son pocas y el contenido de la Enseñanza Fundamental se repite), del Big Bang hasta la mañana de hoy, la historia hace escaso sentido.

${ }^{11}$ Mencionar PCNs. Iniciativas em livros didáticos - Público do Paraná, p. ex. Referenciar. 
Esta "selección" de contenidos poco ayuda a leer el mundo, dificulta mucho e incluso no permite la alfabetización histórica.

La primera versión de BNCC consideró la posibilidad de recorte, de opciones que permitieran cuestionar el presente a partir de las diversas experiencias del pasado, así,

\begin{abstract}
"A Primeira Versão da Base nos dá essa impressão: é possível pensar fora da história quadripartite, da continuidade e do eurocentrismo. Além disso, essa Primeira Versão pensou que as novas gerações têm direitos de aprendizagem: direito a uma memória, direito à justiça, direito a conhecer suas referências e seus pertencimentos, de constituir mesmo uma história para si e para os seus. De reconhecer-se no interior de uma história e também de uma memória. De partilhar lutas, vidas, práticas políticas e culturais. O direito de aprender sobre si mesmo e os outros, de aprender sobre sua ancestralidade, suas identidades"12.
\end{abstract}

Sin embargo, las discusiones y críticas en torno a la primera versión preferían atenerse a la cuestión de qué enseñar, cuál Historia privilegiar, sin tocar a la realidad escolar y sus principales sujetos involucrados: profesores y alumnos. Si la dimensión escolar y el aprendizaje histórico fueran verdaderamente consideradas en la disputa del currículo prescrito tendríamos un debate significativo sobre educación e historia que impactaría nuestra escuela, la formación de profesores y los rumbos de los cursos de profesorado.

\title{
2. La Primera Versión de la BNCC: críticas expresadas en documentos
}

Los últimos meses de 2015 y los primeros de 2016 fueron ocasión para una verdadera ola de textos contrarios a la primera versión de la BNCC - Historia. No podría ser muy diferente, ya que la parte de Historia de la BNCC fue retenida y se retrasó en relación con las demás, y luego de salida fue apuntada por el propio Ministro de Educación de entonces, Renato Janine Ribeiro, como excesivamente ideológica; así, Ribeiro cortó la cinta inaugural de las críticas sobre lo que restaba en la propuesta de Historia. En efecto, la crítica por la falta fue el tema principal del debate. Pero no sólo eso. El hecho de que el ministro diga que la propuesta de Historia era muy "ideológica” (como si

${ }^{12}$ Niton Mullet Pereira y Mara Cristina Santos Rodrigues, "Ensino de História e passado prático: notas sobre a BNCC.” En: Ensino de História e Currículo: reflexões sobre a Base Nacional Comum Curricular, Formação de Professores e Prática de Ensino, ed.Halferd Carlos Ribeiro Júnior y Mairon Escorsi Valério (Jundiaí: Paco Editorial, 2017), 39. 
hubiera habido currículos poco o no ideológicos anteriormente), además de una crítica superficial, fue la contraseña para que movimientos y órganos de prensa tradicionalmente alineados a la derecha concentraran sus baterías en el aspecto político de la primera versión. Aquí destacamos otro punto de contacto con la negación de la ciencia: se ignoró deliberadamente (ya que para Janine Ribeiro no falta erudición) toda la discusión sobre ideología, partidismo y objetividad en las Ciencias Humanas y Sociales. Al hacer una elección por un discurso políticamente más fácil, Ribeiro abrió las compuertas para críticas conservadoras, superficiales e ignorantes del debate académico, apenas algunas de éstas hechas por no académicos, para quienes la ignorancia del debate académico acumulado sobre el tema de la objetividad sería comprensible.

Por orden cronológico, la primera crítica en estos términos vino de Demetrio Magnoli y Elaine Barbosa, con un título dramáticamente panfletario: "Propuesta del MEC para la enseñanza mata la temporalidad"13. Citando Janine Ribeiro, y Aloizio Mercadante, los autores argumentan que, al "retirar" historia antigua y medieval y privilegiar África e indígenas, el documento significaría un rompimiento de la "gramática de la temporalidad". Para ellos, la "retirada" significaría evitar el estudio de la trayectoria occidental, donde se consagraron los principios democráticos como la igualdad ante la ley. El sociólogo y la historiadora escogieron ignorar (pues tampoco aquí se puede hablar de falta de conocimiento o de competencia técnica) primero que aún restó mucho de Occidente en la primera versión de la BNCC, y que los principios democráticos se consagraron y ganaron la forma que conocemos hoy justo en el período moderno, con evidentes consecuencias en la historia de Brasil. En otros términos, la acusación de asesinato de la temporalidad sólo sería procedente si hallaran el cadáver, pero la temporalidad (no la cuadripartita) fue encontrada viva y con salud en la propuesta curricular. Por lo tanto, lejos de una crítica pertinente y colaborativa, el artículo inauguró el linchamiento de la primera versión, recurriendo a un término corriente y lleno de implicaciones en los discursos de derecha: "adoctrinamiento", estorbando a los debates.

Sin contrapunto en la gran prensa, se siguieron otros textos en la misma línea: Ronaldo Vainfas ${ }^{14}$, renombrado historiador y autor de libro didáctico, acusó la propuesta de ser la nueva cara del autoritarismo, y trajo a la discusión dos nuevos términos que colaboran para el esclarecimiento de la línea de

${ }^{13}$ Demétrio Magnoli y Elaine Cenise Barbosa “Proposta do MEC para ensino de história mata a temporalidade.

${ }^{14}$ Ronaldo Vainfas, "Nova face do autoritarismo" O Globo. 5 de diciembre de 2015. 
argumentación: "lulopetismo" y "brasilcentrismo", este último repetido de modo exhaustivo en el debate en la comunidad de historiadores. En ambos textos se puede notar que la crítica es hecha por la identificación de lo que "hace falta", que fue llamada retórica de la pérdida, indicadora del apego al modelo cuatripartita, ocultando su historicidad, así como se nota la ignorancia deliberada de que el currículo es la selección, por lo que mejorarlo no es lo mismo que llenarlo con lo que no está allí. Se sigue el texto de un autor menos famoso, Rafael Diehl ${ }^{15}$, en la Gazeta do Povo, esencialmente con la misma argumentación. Respetado el receso de fin de año, se manifiesta Marco Antonio Villa ${ }^{16}$, cuestionando al "lulopetismo" y alimentando la crítica de la falta. Marcelo Rede ${ }^{17}$ (2016), profesor de historia antigua en la USP, remató el ciclo en el mes del carnaval, denunciando otro asesinato, ahora el de la Historia.

También hubo críticas políticas a la izquierda, con circulación obviamente menor. En el caso de Calii ${ }^{18}$, que denunciaba la falta de marxismo, socialismo y género en la versión preliminar. Con ello, el lector que no estuviera letárgico podía percibir que la "revolución cultural del PT"19 no era tan peligrosa como la mención de la revolución cultural china.

Creemos que ese primer ciclo de críticas públicas no fue correctamente dimensionado en sus consecuencias, principalmente al condicionar, de un modo u otro, las demás críticas de los demás sujetos y con otros intereses y compromisos, que siguieron. Los elaboradores de la primera versión estarían más preocupados por las críticas de carácter más académico y menos político, pero el hecho fue que la primera ola ha dado el tono de las siguientes, tanto en los subterráneos de las redes sociales, (en que alimentó movimientos como la Escuela Sin Partido y varios blogs reaccionarios - una búsqueda por el título de los artículos arriba conduce fácilmente a esas direcciones, en que fueron reproducidos y conmemorados), como en el debate académico. Antecedidos por estos ejemplos, gustando o no de ellos, el hecho fue que la amplia mayoría de los textos que vinieron después de la comunidad universitaria compartieron el carácter demoledor.

\footnotetext{
${ }^{15}$ Rafael M. Diehl, "História sem pé nem cabeça” Gazeta do Povo. 07 de diciembre de 2015.

${ }^{16}$ Marco Antonio Villa, “Revolução Cultural do PT” O Globo. 5 de enero de 2016.

${ }^{17}$ Marcelo Rede, “O assassinato da história” Folha de São Paulo, 29 de febrero de 2016.

${ }^{18}$ Gilberto Calil. Uma História para o conformismo e a exaltação patriótica: crítica à proposta de BNCC /História”. s.l., Blog Junho, 2016.

${ }^{19}$ Marco Antonio Villa "Revolução Cultural do PT".
} 
Pocos textos legitimaron la primera versión como digna de diálogo y de contribuciones para su necesario perfeccionamiento: no se verificó disposición para comprender que era necesario el recorte de contenidos para evitar la sobrecarga enciclopedista, la retórica de la pérdida fue usada al agotamiento, y la crítica política a la primera versión se destacó. En este último aspecto, apareció, por ejemplo, la crítica extemporánea a la propia idea de construcción de una BNCC, definida años antes, en el Plan Nacional de Educación, dentro de un largo proceso, legitimado por la CONAE (Conferencia Nacional de Educación), discutida desde los municipios, involucrando a las más diversas entidades ligadas al área. Pero en general, la crítica destructiva siguió parámetros desafortunadamente típicos en la academia, remontados a la disputatio en que vencer al oponente con las armas de la lógica formal y de la retórica es un objetivo que supera la búsqueda sincera y desinteresada por la verdad, en el sentido de mejor y más motivado argumento. La segunda forma de debatir figuró más raramente, y consiste en identificar los problemas y proponer soluciones conjuntamente, buscar consensos mínimos posibles.

En el camino del carruaje, la crítica de historiadores no conservadores a la primera versión se adhirió, hasta cierto punto acríticamente, al tono polarizado políticamente, aunque se registró formalmente la negativa a ocupar la misma trinchera de organizaciones como la Escuela Sin Partido, la gran prensa y los neoconservadores en general. Sin embargo, se sostuvo el fuego en el mismo blanco que el de ellos, lo que, en la práctica, significó una elección tanto del enemigo inmediato cuanto de los aliados de ocasión.

La predisposición contraria a la versión preliminar en la comunidad académica también se debió a una evaluación de que el proceso estaba demasiado influenciado por fundaciones privadas, sus intereses y sus modelos de educación y sociedad pautados por el mercado, principalmente concentrados en el "Movimento pela Base". Este movimiento fue de hecho uno de los sujetos colectivos, pero dividió espacio con entidades de dirigentes del sector público ${ }^{20}$ y, salvo engaño, no estuvo representado en la versión preliminar de Historia.

No es posible para un texto como ese, dar cuenta de todos los debates, temas y matices de las docenas de documentos producidos en el ámbito de las comunidades universitaria, escolar y editorial. Así, destacaremos los aspectos relevantes para la argumentación que se desarrollará de aquí en adelante, a la relación compleja entre los historiadores y la enseñanza de la historia. No se

${ }^{20}$ Jean Carlo Moreno, "A história na Base Nacional Comum Curricular. Déjà vu e novos dilemas no século XXI”. História \& Ensino. Londrina, v. 22, n. 1, 2016, 07. 
tratará, también, de ignorar las muchas fragilidades de la primera versión, buena parte de las cuales puede ser acreditada a la heterogeneidad del equipo, el poco tiempo para la elaboración y las dificultades referentes al modelo general de redacción de la base y la limitación del tamaño del texto, que no dejó espacio para justificaciones y argumentaciones. Por eso, buena parte de las críticas se basó en el ejercicio hermenéutico de intentar deducir lo que los formuladores quisieron expresar, y en que ellos se habrían basado. Estos ejercicios generaron resultados diversos.

El texto de la Asociación Brasileña de Autores de Libros Educativos, aún en 2015, a raíz de diversas críticas y sugerencias generales y específicas por disciplina, hizo el siguiente balance en cuanto a la historia: el aspecto positivo es sacar el enfoque excesivo del eurocentrismo, y el negativo sería de no permitir a los estudiantes ampliar la idea de sus herencias culturales, corriendo el riesgo de dejar de ser eurocéntrico, pero cayendo en el etnocentrismo ${ }^{21}$. No se deduce inmediatamente, sin embargo, que una propuesta curricular centrada en la historia nacional sea una historia etnocéntrica, ya que Brasil, allí, puede ser entendido como resultando del concurso de diversas etnias e interacciones culturales. Al leer el entero contenido de la primera versión, se deduce fácilmente que éste es el caso, y que no se puede hablar, para este documento, de un nacionalismo tradicional, etnocéntrico por su concentración en solamente un grupo étnico, por ejemplo, el eurocentrismo. Por definición, un etnocentrismo que admite una pluralidad de etnias como "centro" no constituye etnocentrismo.

En la misma línea de la declaración del ministro Janine Ribeiro, la Asociación Brasileña de Estudios Medievales, consideró plausible la crítica de que la propuesta era muy "ideológica". Apunta, entre otros ítems, las posibilidades no eurocéntricas y multiculturales de la historia de África antes del siglo XVI, haciendo hincapié en que la selección hecha en la versión preliminar corresponde a combatir el eurocentrismo, pero se trata de elecciones relacionadas, y no idénticas.

La Asociación Nacional de Historia, sección Río de Janeiro, en su nota, pide el cambio del equipo de la versión preliminar, o su ampliación, y eso se convertiría en una bandera de la dirección nacional de la entidad. En lo que se refiere a la opción de contenidos, establece que

${ }^{21}$ ABRALE, Contribuições da ABRALE para a discussão do texto preliminar da Base Nacional Comum Curricular (São Paulo: ABRALE, 2015), 23. 
"Os estudos da pré e proto-histórias, assim como da Antiguidade e do Medievo - que foram descartados como conteúdos curriculares relevantes - pesquisam as movimentações populacionais entre os continentes, a circulação de ideias e objetos pelo Atlântico, pelo Mediterrâneo, Oceano Índico e até o Mar da China, não podendo ser confundidos com conteúdos eurocêntricos"22.

En este ejemplo, pero también en general, la reducción de Historia antigua y medieval es entendida nuevamente como combate al eurocentrismo, en lo que coinciden con los artículos de periódico arriba mencionados, y ninguna entidad o historiador ha tenido en cuenta la renuncia de la versión preliminar en intentar abarcar "toda la historia" y su disposición de hacer amplios recortes para posibilitar que los contenidos escogidos pudieran ser abordados con tiempo suficiente, cambiando para mejor la relación entre la cantidad de contenidos y la disponibilidad de horas-clase.

El documento de la ANPUH-PR fue el más radical (en el más puro estilo "hay gobierno, soy contra"), exigiendo "rechazo de la propuesta de Base Nacional Común Curricular (BNCC) en Historia presentada por el MEC, teniendo en vista que en virtud del conjunto de las observaciones críticas aquí enunciadas no es posible proponer enmiendas o ajustes a la propuesta en examen”23.

Después de varias cartas, la ANPUH nacional, por fin, definió sus reivindicaciones al Ministerio de Educación en cuanto a la BNCC, asumiendo las banderas de historiadores y entidades de historia de áreas específicas, pidiendo el retorno de los contenidos de historia antigua y medieval, además de una curiosa reclamación en el primer ítem:

“(...) considera-se importante que a segunda versão do documento preliminar do componente História/BNCC:

1) Não reforce as dicotomias tradicionais entre pesquisadores de Ensino de História e de outras áreas da historiografia, buscando arrefecer a clivagem e ampliar o diálogo entre as áreas, contribuindo para dirimir o

${ }^{22}$ ANPUH-RJ, Carta crítica da ANPUH-RIO à composição do componente curricular história na Base Nacional Comum Curricular (Rio de Janeiro: ANPUH-RJ, 2015)

${ }^{23}$ ANPUH-PR, Manifesto público do seminário estadual realizado pela ANPUH/PR sobre a BNCC pela rejeição da proposta de BASE NACIONAL COMUM CURRICULAR para a área de História apresentada pelo Ministério da Educação. Marechal Cândido Rondon (Parana: ANPUH-PR, 2016) 
descompasso identificado em muitas críticas e incorporando os debates historiográficos mais recentes" ${ }^{24}$.

Esta reivindicación, que no corresponde a nada que deba constar en el texto de la BNCC, revela una tensión que entonces se (re) estableció, entre historiadores que se dedican a la historiografía, e historiadores que se dedican la reflexión didáctica, y por lo tanto no componen un área de la historiografía.

Esta relación fue sólo despertada de un sueño latente, pues desde los años 80 del siglo XX, la relación entre Enseñanza e Investigación y su lugar en los cursos de licenciaturas impregna las discusiones sobre la producción del conocimiento histórico, no obstante tal tensión tuvo como punto crucial un momento de crisis política, en un proceso de democratización del país, de recuperación de derechos, donde las reformulaciones curriculares eran urgentes y rediseñaban por medio de debates y disputas, entre otros aspectos, los rumbos de la educación brasileña post dictadura militar.

Las inquietudes actuales provocaron la emersión de antiguos problemas y relevaron que algunas cuestiones que se juzgaban superadas asumieron un ropaje que destaca la cara de la tradición y el peso que ésta representa para los historiadores que ya no quieren diferenciarse de los "historioeducadores", expresión utilizada por Moreno ${ }^{25}$, sino que naturalmente continúan ignorando el lugar, los sujetos y los objetivos y significados de enseñar y aprender historia en Brasil hoy. La solicitud de la directiva de la ANPUH para que se desconsiderara la brecha sólo revela que la brecha sigue viva y fuerte, y que la respuesta encontrada ante esta contradicción para la tarea de representar a los asociados fue ignorarla y pedir que fuera ignorada.

Los documentos citados aquí y muchos otros acabaron condicionando la segunda versión presentada por el MEC en mayo de 2016, ya bajo la administración de Aloísio Mercadante, en los estertores del gobierno de Dilma. El nuevo ministro, dando a percibir de la presión sufrida, anunció que "necesitamos dar énfasis a la Historia Clásica, a nuestra pertenencia a Occidente”, pero considerando también que “Tenemos el tercer país de mayor diversidad étnica y racial del planeta, y esa cultura no tiene el espacio en las

${ }^{24}$ ANPUH, Colaboração da ANPUH Brasil na revisão da proposta da BNCC (São Paulo: ANPUH, 2016)

25 Jean Carlos Moreno, "A história na Base Nacional Comum Curricular. Déjà vu e novos dilemas no século XXI”. História \& Ensino. Londrina, v. 22, n. 1, jan./ jun. 2016, 7 - 27. 
aulas"26. En ese tiempo, la ANPUH consiguió indicar miembros para ampliar el equipo responsable de la Historia en la BNCC, pero estos no aceptaron participar. La parte del equipo original fue entonces despedida, y la segunda versión publicada no correspondió a la revisión que estaba haciendo, pero fue encomendada por la Secretaría de Educación Básica del MEC junto a profesionales que trabajaron en secreto. Así, se perdió la continuidad del proceso, ante las presiones por modificar el texto de la versión preliminar. Prevaleció en el final lo que reivindicó la ANPUH-PR: el abandono completo de la versión preliminar, así como, parcialmente, lo que reivindicó la ANPUHRJ: el cambio del equipo.

La segunda versión, han reconocido nuevos evaluadores, significó un retroceso a moldes anteriores a los PCN, y la versión definitiva, la tercera, apuntó para el retroceso a los años 1970. Los remanentes del equipo original no son autores del texto de la segunda versión de la BNCC-Historia, que fue hecha por asesores ad hoc contratados por el Ministerio.

“[...] a comissão de doze profissionais que produziu a primeira versão da BNCC História foi dissolvida e, em seu lugar, constituída nova comissão, integrada predominantemente por profissionais vinculados a uma única Instituição de Ensino Superior, cujas trajetórias de estudos e investigações não se mostram efetivamente vinculadas ao campo do ensino da História. Para além desse fato, o documento apresentado como uma segunda versão não guarda relações de continuidade com a primeira versão. Razão que nos faz reconhecer nele um outro documento, com pressupostos e proposições bastante distintos daqueles que orientaram a produção inicial da BNCC História. Trata-se de uma proposta que se refugia nos conteúdos convencionais e canônicos, tomando a cronologia linear como eixo central do discurso histórico, ou seja, desconsidera os postulados, princípios e proposições oriundos da pesquisa acadêmica nacional e estrangeira dos últimos trinta anos, representando um flagrante e lamentável retrocesso"27.

Aunque esté implicada la idea de una concepción de clase en la Educación Básica, los debates no tocaron en ese componente que asume un carácter central al pensar el currículo: la dimensión cognitiva de lo que se enseña, articulada a

${ }^{26}$ Citado por Mateus Rodrigues, " $22^{\mathrm{a}}$ VERSÃO da Base Curricular revisa polêmicas de história e de português." O Globo. 3 de mayo de 2016.

${ }^{27}$ Flávia Eloisa Caimi y Sandra Regina Ferreira de Oliveira. "O Ensino de História na BNCC: Pluralismo de ideias ou Guerra de Narrativas?” en: Ensino de História e Currículo, ed. Halferd Carlos Ribeiro Júnior y Mairon Escorsi Valério (Jundiaí: Paco Editorial, 2017), 80. 
cómo se enseña y para quién se enseña. Pero, al contrario, el debate, “[...] esteve inserido e conformado em uma prática reformista conservadora, corroborando um dos mais perversos contextos de desqualificação do debate político da educação pública brasileira”28.

Usando la expresión de Christian Laville ${ }^{29}$, la guerra de las narraciones trajo la superficie, por así decir, de la cuenca, la simbiosis existente entre la universidad y la escuela pues, aunque una serie de resoluciones hayan surgido, así como modificaciones en los cursos de licenciatura desde 2015, fue la BNCC (y su repercusión) que promovió críticas voraces y movió cuerpos arraigados en la defensa de su espacio. Es decir, en ese momento se evidenció en forma de carta abierta vinculadas a las asociaciones científicas, en entrevistas o incluso en espacios colegiados, la temible aproximación entre la narrativa y la organización curricular de los cuadros de los cursos de licenciaturas con el currículo escolar.

"Nesse e em outros casos não se discutiu o direito de aprendizagem dos alunos, mas o que se faria com os professores especialistas nessas áreas, caso a BNCC fosse aprovada da maneira como estava elaborada. A delicada questão expõe um dos problemas mais sérios da formação do professor historiador no Brasil: as maneiras como se aprende História nas universidades e faculdade e as maneiras como se ensina História na Educação Básica”’30.

El impresionante silencio de casi todos los involucrados en el debate de la primera versión, entidades, profesionales y grupos, ante la segunda versión de Historia de la BNCC, que repuso el currículo para un patrón anterior a los PCN, es indicativo de que la discusión interna a la academia guiada se basó principalmente en el interés corporativo, por la crítica demoledora y desinteresada de la solución de los problemas de la primera versión, y en el molde de las primeras críticas, que vinieron de posturas políticas y académicas conservadoras.

${ }^{28}$ Maria do Carmo Martins, "Paradoxos entre Políticas e a Construção do Coletivo: Currículo e a História Ensinada." en: Ensino de História e Currículo, ed. Halferd Carlos Ribeiro Júnior y Mairon Escorsi Valério (Jundiaí: Paco Editorial, 2017), 51.

${ }^{29}$ Christian Laville, "A guerra das narrativas." Revista Brasileira de História. São Paulo, Vol.:19 No. 38 (1999).

${ }^{30}$ Marinelma Costa Meireles y Giovani José da Silva, Orgulho e preconceito no ensino de História no Brasil: reflexões sobre currículos, formação docente e livros didáticos”. Crítica Histórica. N 15 (jul. 2017), 19. 
Parte de ese silencio podría ser atribuido al momento en que se agudizó la discusión del impeachment, reconocido como golpe por la amplia mayoría de la comunidad de Ciencias Humanas y Sociales. Sin embargo, cabe la incómoda tarea de hacer ese cuestionamiento: por disparar en el mismo blanco, aunque buscando preservar una trinchera diferente, por el tono destructivo de la crítica, aunque preservando que la destrucción no era la misma promovida por Villa y los otros historiadores acogidos por la gran prensa, por el silencio cuando salieran la segunda y tercera versiones de la BNCC - Historia... ¿no tendríamos dado nuestra cuota de colaboración (aunque preservada la contrariedad) para el punto en que hemos llegado en términos de currículo?

La expectativa es que de esa arena de ataques y disputas podamos ver más allá de la superficie y unir fuerzas en beneficio de una formación escolar y universitaria sólida que permita además de contenidos y acumulaciones de informaciones desarrollar el pensamiento histórico de los brasileños y brasileños que luchan para sobrevivir diariamente frente a tantas desigualdades.

\section{Consideraciones finales}

Devemos fazer tábula rasa do passado? ${ }^{31}$ La comunidad de historia demostró que no alcanza a superar el esquema cuatripartita. Puede criticarle, pero no está lista para superarlo concretamente.

Fue injustamente generalizada la idea de que el recorte de antigua y medieval corresponde inmediatamente a una actitud anti-eurocéntrica. En realidad, es posible que el eurocentrismo sobreviva en las otras partes del recorte. Por ejemplo, la tradicional historia de Brasil es eurocéntrica. No se consideró, por lo tanto, que no se trata simplemente de "intercambiar" antigua y medieval por África e indígenas, sino de descolonizar la enseñanza de la Historia de Brasil redimensionando la contribución de negros e indios para revisar la narrativa canónica, en la escuela, de la tradicional historia nacional. Así, el peyorativo término "brasilcentrismo" no constituye demérito de la propuesta, pero, nuevamente, una elección innovadora.

En contextos como el vivido por la comunidad de los historiadores, la brecha entre historiadores "stricto-sensu" e historiadores dedicados sustancialmente al campo de la enseñanza de la historia, ¿cómo queda el poder de representación de una entidad que reúne a los dos grupos, como es el caso ANPUH, cuando tiene que elegir la demanda de uno de ellos para encaminar al poder público?

${ }^{31}$ Jean Chesneaux, Devemos fazer tábula rasa do passado?-Sobre a história e os historiadores (São Paulo: Ática, 1995). 
¿La recomendación de la directiva nacional para que se evitase considerar la brecha entre investigadores de historia e investigadores de la enseñanza de la historia tiene qué significados y consecuencias, efectivamente? ¿Siempre en la disputa de concepciones y / o intereses, los primeros tendrán su posición representada por la entidad, dado que son en mayor número de asociados? ¿Si no lo hace, la ANPUH puede ser considerada democrática? ¿Habremos, en ese emblemático caso, llegado al agotamiento límite de las posibilidades de representación de la entidad para esos dos grandes grupos? Si es así, la negación de sus diferencias es el único camino para seguir representando a ambos, pero este es el camino más seguro para no representar el segundo grupo.

Se debe considerar, además, que la discusión en pantalla fue hecha en el tono de la coyuntura histórica especial en que se dio. En nuestro punto de vista, el exceso de consideraciones corporativas se superpuso a la necesidad de pensar y actuar táctica y estratégicamente, tras un buen análisis coyuntural. En la ausencia de estos procedimientos, evaluamos que las críticas académicas a la primera versión contribuyeron con dosis de deslegitimación y desestabilización que fueron importantes para que se configurara el retroceso que significó la segunda, pero principalmente la tercera versión de la BNCC - Historia. Evidentemente, no se trató de condición suficiente para ello, pero su papel no puede ser menospreciado.

Por último, convivimos con procesos de negación de la ciencia que son culturales y diseminados por la sociedad, y que sirvieron para el proceso de deslegitimación de la primera versión y de sus autores. La contraseña fue la palabra "ideología", lanzada por el ministro Janine Ribeiro, asociada, acto continuo, al término "adoctrinamiento". La negación de la ciencia asume, en el caso de las Ciencias Humanas y Sociales, la negación de sus científicos por la acusación de "izquierdismo”, entre otras formas y estrategias. Pero ¿cuánto hay, internamente, de negación de la ciencia entre los historiadores? ¿Cómo explicar que todas las especialidades en Historia se sienten cómodas en discutir otra especialidad sin leer su producción acumulada o consultar a sus especialistas? Si los especialistas en enseñanza de la historia entraran en el debate sobre la historiografía antigua o medieval ignorando la producción y el estado actual de la cuestión, ¿¿cuál sería la reacción de los investigadores de esas áreas? Por lo tanto, al rechazar el criterio que, para entrar en un debate referente a un campo al que se dedican los colegas historiadores, debemos informarnos del estado actual de la discusión, de los acumulados y de los principales polemistas y sus posiciones, terminamos por rechazar el propio reconocimiento de que 
mis colegas sean mis colegas, es decir, científicos tan merecedores de respeto y atención a su producción como yo. Intencionalmente o no, fue lo que se dio.

La sin-ceremonia con que se ignoró la enseñanza de la historia como campo de investigación, de producción de conocimiento y de acumulación de discusión de políticas públicas por tantos polemistas es un síntoma preocupante de que el campo no es reconocido por amplios contingentes de historiadores "stricto "sensu", quizá la mayoría. La negación, por una parte, significativa de los historiadores, de la concesión de status científico a las reflexiones e investigaciones hechas por los profesionales que se dedican a la investigación de la enseñanza y del aprendizaje de la Historia es el tema central aquí. Si fuera aceptado como campo de investigación y producción de conocimiento del mismo nivel que el de los críticos de la primera versión, la enseñanza de Historia debería ser reconocida como la posición prioritariamente destacada entre los historiadores para opinar sobre la BNCC. Al final, no se trataba de Historia Antigua o Medieval, sino más bien, de objetivos y medios para la enseñanza de la historia. No es sorprendente que esa negación de la ciencia producida por los otros sea compatible con un elemento muy presente en la cultura laboral de los historiadores, que es la idea de que la enseñanza es aplicación, es simplificación y didactización retrasada de lo que el historiador produce. Nos parece que el enfrentamiento de ese problema de identidad-pertinente a los dos grupos- será la cuestión decisiva para enfrentar si lo que se busca es una representación unitaria y potente de todos los profesionales de la historia. Un buen comienzo sería rememorar los esfuerzos de Déa Fenelon y tantos otros directores para alcanzar el inestimable avance que fue la incorporación de los profesores de historia no universitarios a la entidad, así como la creación, posteriormente, de un Grupo de Trabajo en Enseñanza de Historia. No como invitados que se aceptan, sino especialistas en un campo de la historia en profunda interacción con la sociedad, asunto sobre el cual deben ser prioritariamente escuchados.

\section{Referencias bibliográficas}

\section{Fuentes secundarias}

ABRALE (Associação Brasileira dos Autores de Livros Educativos). Contribuições da ABRALE para a discussão do texto preliminar da Base Nacional Comum Curricular. São Paulo: ABRALE, 2015. [en línea] http://www.abrale.com.br/wp-content/ uploads/BNCC-contribuicoes_Abrale_final.pdf

ABREM (Associação Brasileira de Estudos Medievais). Carta da ABREM sobre a Base Nacional Comum Curricular (BNCC). Niterói: ABREM, 2015. [en línea] http:// 
livrozilla.com/doc/1540512/carta-da-abrem-sobre-a-base-nacional-comum-curricular

Amézola, Gonzalo de. Esquizohistoria. La Historia que se enseña en la escuela, la que preocupa a los historiadores y una renovación posible de la historia escolar. Buenos Aires: Libros del Zorzal, 2008.

ANPUH-RJ (Associação Nacional de História - Seção Rio de Janeiro). Carta crítica da ANPUH-RIO à composição do componente curricular história na Base Nacional Comum Curricular. Rio de Janeiro: ANPUH-RJ, 2015. [en línea] http://rj.anpuh. org/download/download?ID_DOWNLOAD=1614

ANPUH-PR (Associação Nacional de História - Seção Paraná). Manifesto público do seminário estadual realizado pela ANPUH/PR sobre a BNCC pela rejeição da proposta de BASE NACIONAL COMUM CURRICULAR para a área de História apresentada pelo Ministério da Educação. Marechal Cândido Rondon: ANPUH-PR, 2016. [en línea] http://www.pr.anpuh.org/arquivo/download?ID_ARQUIVO=61986

ANPUH (Associação Nacional de História). Colaboração da ANPUH Brasil na revisão da proposta da BNCC. São Paulo: ANPUH, 2016. [en línea] https:// anpuh.org.br/index.php/2015-01-20-00-01-55/noticias2/noticias-destaque/ item/3307-colaboracao-da-anpuh-nacional-na-revistao-da-proposta-da-bncc

Caimi, Flávia Eloisa e OLIVEIRA, Sandra Regina Ferreira de. "O Ensino de História na BNCC: Pluralismo de ideias ou Guerra de Narrativas?” En: Ensino de História e Currículo: reflexões sobre a Base Nacional Comum Curricular, Formação de Professores e Prática de Ensino. Ed. Halferd Carlos Ribeiro Júnior y Mairon Escorsi Valério. Jundiaí: Paco Editorial, 2017.

Calil, Gilberto. "Uma História para o conformismo e a exaltação patriótica: crítica à proposta de BNCC /História”. s.l., Blog Junho, 2016. [en línea] http://blogjunho. com.br/umahistoriaparaoconformismoeaexaltacaopatrioticacriticaapropostad ebncchistoria/

Chesneaux, Jean. Devemos fazer tábula rasa do passado? - Sobre a história e os historiadores. São Paulo: Ática, 1995.

Cleto, Murilo. “Quem tem medo de outra História?”. Revista Fórum, N. 230, 2016. [en línea] https://www.revistaforum.com.br/semanal/quem-tem-medo-de-outrahistoria.

Diehl, Rafael M. "História sem pé nem cabeça”. Gazeta do Povo. 07 de diciembre de 2015. [en línea] http://www.gazetadopovo.com.br/opiniao/artigos/historiasemp enemcabeca97bl0cd523od0a3ste97ccu82

Fonseca, Selva Guimarães. Caminhos da História Ensinada. Campinas: Papirus, 1993.

Frigotto, Gaudêncio. "A gênese das teses do Escola sem Partido: esfinge e ovo da serpente que ameaçam a sociedade e a educação." En: (org.). Escola "Sem" Partido: Esfinge que ameaça a educação e a sociedade brasileira. Rio de Janeiro: UERJ, LPP, 2017.

Laville, Christian. "A guerra das narrativas." Revista Brasileira de História. São Paulo, Vol.19, No. 38 (1999): 125-138. 
Lewandowski, Stephan; Oberauer, Klaus y Gilles Gignac. "NASA Faked the Moon Landing-Therefore, (Climate) Science Is a Hoax: An Anatomy of the Motivated Rejection of Science." Psychological Science, Vol. 24, No. 5 (2013): 622-633.

Magnoli, Demétrio y Elaine Cenise Barbosa. "Proposta do MEC para ensino de história mata a temporalidade". Folha de São Paulo. 8 de noviembre de 2015. [en línea] http://www1.folha.uol.com.br/ilustrissima/2015/11/1703011-proposta-do-mec-para-ensino-de-historia-mata-a-temporalidade.shtml

Martins, Maria do Carmo. "Paradoxos entre Políticas e a Construção do Coletivo: Currículo e a História Ensinada." En: Ensino de História e Currículo: reflexões sobre a Base Nacional Comum Curricular, Formação de Professores e Prática de Ensino,ed. Halferd Carlos Ribeiro Júnior y Mairon Escorsi Valério. Jundiaí: Paco Editorial, 2017.

Meireles, Marinelma Costa e Silva, Giovani José. "Orgulho e preconceito no ensino de História no Brasil: reflexões sobre currículos, formação docente e livros didáticos”. Crítica Histórica. No. 15 (jul. 201), 7-30.

Moreno, Jean Carlos. "A história na Base Nacional Comum Curricular. Déjà vu e novos dilemas no século XXI". História \& Ensino. Londrina, v. 22, n. 1, jan./ jun. 2016, 7-27.

Morrison, David. "Science Denialism: Evolution and Climate Change". Reports of the National Center for Science Education, Vol. 31, No. 5 (sept.-oct. 2011): 31-40.

Pereira, Nilton Mullet y Mara Cristina Rodrigues de Matos. "Ensino de História e passado prático: notas sobre a BNCC." En: Ensino de História e Currículo: reflexões sobre a Base Nacional Comum Curricular, Formação de Professores e Prática de Ensino, ed. Halferd Carlos Ribeiro Júnior y Mairon Escorsi Valério. Jundiaí: Paco Editorial, 2017.

Rede, Marcelo. “O assassinato da história”. Folha de São Paulo, 29 de febrero de 2016. [en línea] http://www1.folha.uol.com.br/opiniao/2016/02/1744204oassassinatodahistoria. 19/03/2016.

Rodrigues, Mateus. " $2^{\mathrm{a}}$ VERSÃO da Base Curricular revisa polêmicas de história e de português." O Globo. 3 de mayo de 2016. [en línea] https://g1.globo.com/ educacao/noticia/mec-apresenta-segunda-versao-da-base-nacional-comum-curricular.ghtml

Vainfas, Ronaldo. "Nova face do autoritarismo". O Globo. 5 de diciembre de 2015. [en línea] https://oglobo.globo.com/opiniao/nova-face-do-autoritarismo-18225777

Villa, Marco Antonio. "Revolução Cultural do PT". O Globo. 5 de enero de 2016. [en línea] https://oglobo.globo.com/opiniao/a-revolucao-cultural-do-pt-18407995 
